\title{
Dr. Zefei Jiang: our journey beyond the stars and seas
}

Received: 04 February 2020; Accepted: 25 February 2020; Published: 10 April 2020.

doi: $10.21037 /$ tbcr.2020.03.01

View this article at: http://dx.doi.org/10.21037/tbcr.2020.03.01

\section{Introduction}

In a swimming contest, before the contestants reach the finish line, they can see a yellow line, someone may have already crossed it, or it's about to be passed by someone.

Apart from being a doctor and a medical educator, Dr. Zefei Jiang (Figure 1) had just added a new role to himself, editor-in-chief of a medical journal, this was his way of pushing his yellow line a little closer to the finish line.

In the community of breast cancer, Dr. Jiang is not a name you've never heard of, you can always find him at breast cancer conferences held in China, the United States, and European countries, at occasions where important medical guidelines and consensuses are released, as well as in consulting rooms, patient wards, and beside hospital beds.

During the transition of different scenarios, Dr. Jiang has become the "greatest common divisor" among his various roles. When these roles are intermingled with each other, he has become a "unique element" that appears impossible but is existent.

"Although I have multiple identities, my primary role is a doctor, and this will never change. Since I have a new role as editor-in-chief of a medical journal, I will always think of this journal-when there is an academic dispute, I will be wondering whether it can be discussed in the journal. When I see a hot topic, I would think I should invite an expert to make a commentary. When I come across a case, I would contemplate on whether I can make a case report and share it with my peers. When I hear an excellent lecture, I would wonder whether the presenter is a right candidate for our editorial board".

\section{Male doctor and female patients}

When Dr. Jiang graduated from the First Military Medical University (Now Southern Medical University) in 1987, the surgical department was his preferred department to work for. However, he was assigned to the 307 Hospital of the People's Liberation Army (Now the Fifth Medical Center of the PLA General Hospital), and the hospital had only five departments, including the hematology and oncology department. At that time, most patients admitted

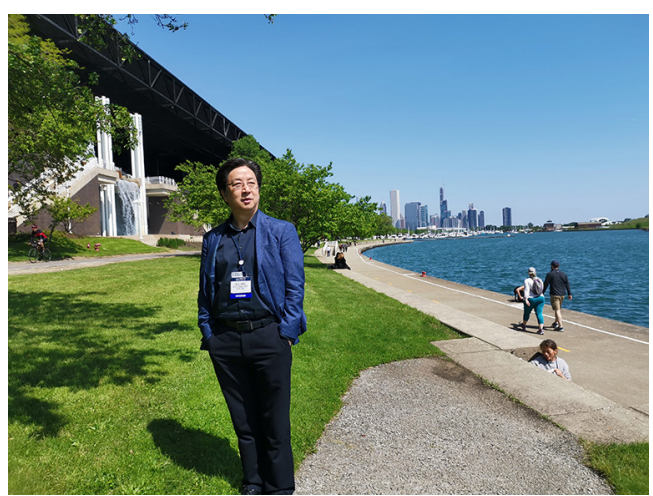

Figure 1 Prof. Zefei Jiang, MD.

to the oncology department were terminally ill, and much of the job was related to hospice care. Therefore, many doctors were reluctant to be assigned to this department. However, Dr. Jiang believed that oncology was an emerging department, and he could acquire an abundant of new knowledge in the department. Nevertheless, he stressed that if he had the chance to choose again now, he would probably still prefer to work at the surgical department.

After the dream of working at the surgical department failed to come true, Dr. Jiang was facing another dilemma: the hospital had begun to admit breast cancer patients since 1980s, and the department chief Prof. Santai Song established China's first department of breast cancer at the hospital; that meant he would have to deal with mostly female patients, although sometimes there were rare cases of male patients.

In the beginning, he was "obliged" to work at the oncology department, gradually, he had adjusted to the idea, and eventually, he led the department in gaining a nationwide reputation. That has been a history of some 30 years.

"Many female patients with breast cancer are asking the same question - whether they should seek belp from a male doctor or a female doctor. Whether they should find a doctor of the same generation or different generations?" This is not a joke, Dr. Jiang said, adding that researchers had conducted a study regarding survival rates of surgeries performed by female 
doctors and male doctors. He held that the answer depends on the patient's attitude. "If you are acquainted with a certain male doctor and feel uncomfortable to seek help from him, you can find a female doctor; if you simply want help from the best doctor, the gender of the doctor is not the ultimate determining factor." Whatever the choice is, he believes that he has developed the ability of reading his patients' minds, "when patients come into the room and sit down, I take a glance, and I can get an overall idea of their expectations, their attitude towards life and the kind of therapy they need."

Since becoming a doctor, Dr. Jiang has been extremely popular among female patients. As relatively young doctors we've gained particular advantages, "Elderly ladies will see us as their son, young girls would see us as reliable uncles, and with patients of similar age, we would have a better understanding of their real life concerns. So, I feel lucky to have earned the trust of so many patients."

Dr. Jiang now receives 4,000 patients a year. He has treated about 100,000 patients throughout his career. Behind these statistics, he has witnessed the fickleness of human nature, "Some husbands remained firmly devoted to their wives, some filed divorce soon after they learned that their wives were diagnosed with breast cancer, and some have been continuously taking care of their diagnosed loved ones even though their marriage has ended many years before that." Breast cancer is common among women. Dr. Jiang stated that in addition to the treatments of the disease, we should also pay special attention to the series of social problems related.

"Are there any side effects on patient prognosis if they go square dancing? I would call it a positive "side effect", because when we are in a good mood we have the urge to dance, and dancing, will make you even happier; when patients play mahjong, they would probably have a higher win-rate, because imagine beating someone who recently defeated breast cancer; the more they win and the more confidence they gain, they would likely be in a more content state of mind."

He considers psychological adjustment and communication is undisputedly essential to patients; apart from the treatment itself, future research should also focus on patients' mental needs, "This is important because if the patients aren't in a relatively healthy and stable mental state, even the best therapies are doomed to fail."

"If you challenge the 'norms' and think outside the box, you might end up gaining more." Dr. Jiang said that during a conference a few days ago, he discussed with some experts about preoperative chemotherapy for breast cancer patients, and he asked a question, "after chemotherapy, Which is it a better scenario, the shrinking of the tumor or the softening (reduced density) of one?" Most people consider the tumor shrinking a better result. But in fact, a softened tumor might be a better outcome for the patient, because it could mean that most solid cancer cells have been killed, and the remaining cells are easier to deal with. While a tumor may shrink in a diffuse way rather than in a centripetal manner, its residue may persist. Therefore, Dr. Jiang stressed, "We should always reconsider our predisposed ideologies and challenge them, perhaps then we can uncover new understandings!"

With more than three decades of a career as an oncologist, the fifty-three-year-old Dr. Jiang said he has "a little more regrets than achievements". "I'm not saying that we have to be haunted by our regrets, these regrets give us an indication of what we can do in the future; and the biggest achievement we can hope for is a growing awareness of our own limitations."

Dr. Jiang recently gave a speech and shared a view: research can optimize clinical practices; to make that happen, we have to do the work in five aspects "Basic (pre-clinical) research, translational research, randomized controlled trials, big real-world data, and Artificial Intelligence." He thought for a moment during the interview, saying he might not be the most suitable candidate in regards to the field of basic research and translational research compared to other researchers, but he can put more effort into the other three areas.

"Each professional has their own expertise. Our five fingers are not the same length, so why not use the advantages I have gained over the years? - the solutions to patients' illness, the experience in developing diagnosis \& treatment guidelines and consensuses, as well as tens of thousands of patient cases-I can make good use of them in developing new clinical studies, sum up real-world data, gather big data, and explore the application of Artificial Intelligence within a clinical context."

\section{Teacher and students}

In the hospital, he is always dealing with female patients, but a vast majority of his current students are male. Because of his other identity—an army officer.

Jianbin $\mathrm{Li}$, who began a doctoral study in 2015 and is now conducting his postdoctoral research at Dr. Jiang's department, commented, "Because it's a military affiliated hospital, most students are male." Jianbin Li secured a master's degree in breast surgery in 2015 from the 307 Hospital of the People's Liberation Army, and he chose Dr. 
Jiang as his mentor for his doctoral study. Nevertheless, he chose Prof. Jiang, not for his "well-known fame," but because "his postgraduate mentor was not qualified to take doctorate students, and he was unwilling to give up research into breast illness, so he chose Prof. Jiang to be his mentor."

Although they did not know each other well at the time, they eventually became acquaintances and friends. As Dr. Jiang's first doctoral student in the army, Jianbin Li, claimed that he "understands" his tutor well, "I don't know why, perhaps we just get along well with each other. I understand a lot of his methods. Prof. Jiang also gave me enough trust." Jianbin Li still remembers that his first job from his tutor was to take part in a debate contest organized by the Department of Breast Surgery of Peking Union Medical College Hospital. "He was aware that I was still a newcomer in the academic arena, but he gave me a vote of confidence." After that, Jianbin Li has become increasingly confident, and he earned his trust from his tutor.

It is said that your teacher amounts to your father. After years of working alongside each other, many students have regarded Zefei Jiang as their father. Prof. Jiang has brought them not only the change of identity from a student to a professional but the change of "insight." "During the postgraduate study, we've spent most of our time focusing on surgeries and clinical work; after carrying out our doctorate research under the mentorship of Prof. Jiang, we have received more academic exchange opportunities with our peers and grown-up rapidly." Thanks to his participation in the Chinese Society of Clinical Oncology (CSCO)'s Breast Cancer Committee (CSCO BC), Jianbin Li said that students like him could climb to a higher level and make some accomplishments and even changes to clinical practices.

During the three-year doctoral study, Jianbin Li had presented at three CSCO conferences and two CSCO BC meetings. "This was unimaginable for me in the past. I'm grateful to my mentor for his dedicated support and recommendations so that I can do a lot of things."

Since 2016, Jianbin Li and several other students of Prof. Zefei Jiang have undertaken various jobs at CSCO BC. It is through such practices that they have truly realized the significance of this platform to the development and progress of breast cancer diagnosis and treatment in China. "For example, we used to think that clinical research data guide clinical practice, and clinical research data have been designed beforehand. The drugs prescribed and their doses are fixed. However, each patient differs case by case. When we have established the use of database and big data, we can make some real-world analysis and figure out a drug's clinical efficacy and dosage. Besides, when an advanced cancer patient is not physically equipped for clinical studies, should we rule him/her out? In fact, with big data and the application of Artificial Intelligence, we can enroll more patients." According to Jianbin Li, these jobs conducted with the help of CSCO BC can make up for frontiers that cannot be reached within the fields of clinical or fundamental research.

Dr. Jiang is known for being a stern and strict mentor. But these students have never complained because "Since a lot of them are more or less of the same age as Dr. Jiang's daughter, it is necessary that he put in much needed effort into helping them grow rapidly." The students are deeply aware of their mentor's good intentions.

In the workplace, they might feel jittery in the presence of their mentor; yet, when they're in the office face to face with him exchanging pleasantries about their own families and future plans, "it's a moment of warmth and comfort." There is an old saying that "In the Yangtze River, the waves behind drive on those before, and the waves before are subsiding on the beach," but Dr. Jiang had always "hoped his students could stand on his shoulders and take on more responsibilities, and a sound echelon of talent cultivation can be established."

In the eyes of his students, Dr. Jiang is not only a mentor who takes leadership during academic researches but also a friend who can go on road trips with, enjoy hot-pot dinners with, and play fun games with, as well as a tutor who's willing to pay close attention to your work, study, and future plans. Jianbin Li recalled that he was asked to give a lecture at the CSCO annual conference in 2018. "I was scheduled to make a report at the last forum, and Prof. Fiang was originally supposed to present a lecture at another session, but when I was on the podium, I saw him staying in the audience photographing me presenting. After the report, be offered to take a photo of him and me together-that was a rare gesture for him because be seldomly asks to be photographed with others." Jianbin Li said it was an especially fruitful event for him as he received an unexpected gift from the tutor at the forum. "I forgot to wear a tie and borrowed one from a classmate for the event. He noticed that I was wearing a tie I had never worn, and I told him it was borrowed. After the conference, be offered to treat us all at a restaurant and it was during then when he gifted me a brand-new tie to celebrate my extraordinary performance at the presentation." As we've all said, he had taken care of his students like a loving father to his own children.

Jianbin Li has been studying with Prof. Jiang for five 
years, in his eyes, his mentor is still "sharp as a tack." "Whether it is a case review or an expression of opinions, Prof. Jiang has always been able to hit the spot. If he can use one sentence to explain his views, he will not use two; if he can use two, he will not use three. When it comes to academic issues, he is both earnest and rigorous, but this has not undermined his reputation in the medical community, because everyone is clear that the more truth is debated, the clearer it becomes." However, Jianbin Li and several classmates have felt that their mentor has become "gentler" since 2016. "Perhaps after he turned 50, he has a more distinct understanding of what he wants to do and what he doesn't want to do."

At 29, Jianbin $\mathrm{Li}$ is now the youngest member of CSCO BC; 24 years ago, Dr.Jiang was also 29 years old when he took the helm of the Department of Breast Surgery at 307 Hospital of the People's Liberation Army and became the youngest department head at the hospital.

Perhaps after this, countless other young doctors would also set sail at the age of 29 , and they all share the same title-students of Dr. Zefei Jiang.

\section{Editor-in-chief and his dream}

"If you want to take part in a bigh quality conference, you can bold one."

"If you want to read a good book, you can write one."

This was a conversation between Dr. Jiang and one of his friends several years ago. He believes that rule also applies to a medical journal.

About five years ago, AME Publishing Company's founder Daoyuan Wang and DXY founder Tiantian Li discussed with him about publishing a medical journal, "But I declined their invitation," recalled Dr. Jiang, because I thought I was unprepared at that time."

"Waiting is a gamble with time." After a period of waiting, the result has become more precious. When the clock ticked into 2019, he saw a glimpse of hope. "The timing is mature, from the perspectives of national policies, academic progress, and personal development."

According to a statement released after the fifth meeting of the Central Committee for Deepening Overall Reform, which was presided over by Jinping Xi, General Secretary of the Central Committee of the Communist Party of China and President of The People's Republic of China, "science \& technology journals inherit human civilizations, gather scientific discoveries, and spearhead the development of science and technology, and thus they are a direct indicator of a country's technology prowess and cultural soft power. It was urged that China should set the goal of producing world-class academic journals, compiling the catalog of critical periodicals, and publishing a number of journals in basic research and traditionally leading areas." "The central government has outlined the top-level policy framework. We should have confidence in publishing academic journals in line with international standards and hailed by industry communities."

Zefei Jiang stressed, "Rather than pursuing 'overseas recognition,' we should instead understand that overseas recognition is not equivalent to international recognition; China is no longer what it was in the past." In the past, most Chinese doctors learned about medical developments in foreign countries through reading reports by peers who've returned from international conferences, but it has changed. "Many of our nation's medical professionals are invited to present at global academic conferences and play roles in discussing and developing international expert consensuses."

In addition to these external factors, Zefei Jiang reckoned that our confidence also stems from the continuous development and expansion of CSCO BC. Today the database on the CSCO BC platform has included some 60,000 cases. "With such tremendous amount of data, we can explore more and more ideas and researches, so why don't we display our strength at our own platforms?"

However, "our problem is that even with novel research ideas, they might not get publicized, because we have to wait before a crowded queue to get our research articles published, and there are only a bandful of journals worldwide." Dr. Jiang acknowledged that it is not only a formidable challenge for the CSCO BC team and himself but also a common dilemma for many Chinese researchers.

According to Zefei Jiang, clinicians are primarily driven by external pressure to do research. For instance, students count on them to graduate; doctors have to produce scientific articles to get a senior title, and scientists hope to make research breakthroughs to win awards. Scientific research has become a symbol of a medical scholar's development process. But now he feels that more scholars see the pressure as a kind of internal motivation, "Disregarding the so-called pressure factors, for a scholar, no matter how strong his clinical skills and academic strength is, he must always leave behind some landmarks to prove himself." Therefore, "their desire is more often spontaneously driven by their own aspirations."

Besides, Zefei Jiang said the "driving force" could also stem from interest and hobbies. "Under the current healthcare 
system in China, we are dealing with a lot of real-world cases every day." He added, some cases are rare but significant for reference; if we do not report and share them, they may be gradually ignored. He stressed that these cases could be either successful experiences or painful lessons, "either way, the most important thing is that these clinical experiences can be applied to future cases."

Zefei Jiang shared a little story. Several years ago, he attended a meeting in a northeastern city and sit next to an expert in digestive system tumor. During casual conversation, he learned that the expert was using an effective drug against patients' intractable diarrhea when treating gastrointestinal tumors. Coincidentally, he had a hospitalized patient who was troubled by acute intractable diarrhea, and the drug also turned out to be especially useful for relieving the symptom. This was especially noteworthy for Dr. Jiang. "When we conduct research, we tend to be intensely focused on our territories; instead, we should exchange views with peers outside our own field, considering how inspiring it often is."

When our conversation shifted to scientific research, Zefei Jiang smiled and said that his acquaintance with $\mathrm{Mr}$. Daoyuan Wang, the founder of AME Publishing Company, also took place at a research training session. "He and I often cross paths during these sessions. Many doctors who had received training at that time later became there fields' leader." Now more than a decade has passed, our goals and directions of training have changed a lot. "We have changed from analyzing other people's articles to training people on how to write articles about their own experiences and ideas." Dr. Jiang believes this has also become a reasonable basis for mutual cooperation.

"After these five years, why did you finally make up your mind on collaborating?"

"We always say that people should think carefully before taking actions; this is true. But if we keep thinking and do nothing, we will probably end up being stuck."

"Do you have any plans about how to overcome the challenges above?"

"Yes, through time, energy, funding, and source of essays; these are major challenges. Perhaps the journal may end up balted balfway."

"So, what to do?"

"If we are determined to do something, we must have a firm belief that our resolution and determination can belp us overcome the challenges: if we don't have enough funding resources, we can sell everything we have; without enough articles, we can ask for belp everywhere; I believe that as long as we have a firm belief, favorable external and internal environments, and high academic influence, we can work together to overcome every challenge on the way."

Besides, Dr. Jiang said that AME's substantial experience in journal publications over the years was also a determining factor behind his decision to run a journal. "You have over 60 English journals and a well-established and excellent editorial team, and your style collide well with mine. I once read an AME journal, everything from cover design choices to operational ideas were in line with my expectations."

Regarding the positioning and editorial styles of the Translational Breast Cancer Research (TBCR), Dr. Jiang said he doesn't like dragging things out, "If I have decided on something, I must offer something concrete. I can tell you what the consensus were, and where we still have some disagreements, and what we need in the future. Therefore, I hope we can publish some 'real' articles, not just those with positive results; we should also share articles with negative results as long as they have referential values. Like a bump in the road we can warn others about or smooth out ourselves." Dr. Jiang insisted that a journal must have distinct characteristics, and the editor-in-chief's responsibility is to develop these features.

In addition to completed researches, research programs still in development can also be published in the journal. "In a new field, we propose new concepts and innovative ideas, and allow other parties to challenge our opinions, and we would provide data and practices to support our claims. After important research is released, we also offer a platform for discussions and debates from people with different views, and we can discuss future problems and the plan's shortcomings." That is to say, "we hope to bring something inspirational and enlightening."

In conclusion, Dr. Jiang said the core elements of a journal are "hot topics" and "disputes." Separate columns should be arranged for these two elements. For instance, we can create a column dedicated to one or two hot topics, such as whether androids can be used to perform breast cancer surgeries and the opportunities and challenges for the clinical application of Artificial Intelligence. Concerning disputes, he said, "We hope to offer a platform for explaining views that might not be accepted by the majority, , we have to verify in which cases the minority possesses the truth."

"What's your expectation for the journal?"

"I hope it can reach a wide audience and capture the attention of professionals, and many doctors will they want to keep it and take a good look."

"A bundred years later, what do you want others to say about the journal?"

"Some people claim that paper books and journals will 
eventually disappear in the digital age, while others say that hard copies will remain forever. Future generations might think that their ancestors were quite energetic in leaving them something interesting to enjoy; perhaps they still prefer to read hard-copy books and journals. The precondition, of course, is that the journal will continue to be published a bundred years later. Let us leave the right to judge to our future generations."

"Hard copies are ceremonial. for instance, when two people part ways with each other, either for a brief period or a long time, paper letters and photos can preserve those fond memories in a physical sense". Jiang added.

\section{Afterword}

Having been acquainted with Prof. Zefei Jiang for quite a few years. In his words, our encounter was an experience of "no discord, no concord."

That was my first attendance at the CSCO annual conference. Due to my carelessness, I might have "offended" Prof. Jiang. As a result, we did not leave a good first impression on each other. However, we later forged an indissoluble bond with each other.

Between 2007 and 2017, I had done 36 interviews with Prof. Jiang. This time, because of TBCR, I came again to the office that I have been made familiar with. For a moment, I thought it was 12 years ago when I visited the office for the first time.

Prof. Jiang is still high-spirited and vigorous. Some gray hair can be seen on his head, but he still looks fearless and heroic. He has appeared to be amused by about the complimentary remarks on his "handsomeness" from a young coworker of mine in her 20s who accompanied me during the interview.

Like before, Prof. Jiang had asked that our interview be split into several sections because of the numerous patients coming to his office and asking for help. He is more of a doctor nicknamed "Big Jiang," sometimes animated, sometimes stringent- $-\mathrm{He}$ can be humorous this moment, and he can be vigorous a minute later.

Twelve years have passed, and everyone is struggling and moving toward the direction they think is right.

But we are not stopping because "our journal goes beyond the stars and seas."

We have seen the vast stars and will eventually reach the uncharted sky.

We have set sail to the sea and will embark on a journey to the sea.
I do not drink alcohol anymore

I do not complain about the poor life anymore

Get rid of tiredness

Common but courageous

I am also a young man here

Smile to the world

- "I am also a young man bere"

\section{Acknowledgments}

I would like to express my heartfelt gratitude to Dr. Zefei Jiang for accepting this inter-view. Also, thanks to TBCR for giving me this opportunity.

Funding: None.

\section{Footnote}

Provenance and Peer Review: This article was commissioned by the editorial office, Translational Breast Cancer Research. The article did not undergo external peer review.

Conflicts of Interest: The author has completed the ICMJE uniform disclosure form (available at http://dx.doi. org/10.21037/tbcr.2020.03.01). The author reports that she is a full-time employee for AME Publishing Company.

Ethical Statement: The author is accountable for all aspects of the work in ensuring that questions related to the accuracy or integrity of any part of the work are appropriately investigated and resolved.

Open Access Statement: This is an Open Access article distributed in accordance with the Creative Commons Attribution-NonCommercial-NoDerivs 4.0 International License (CC BY-NC-ND 4.0), which permits the noncommercial replication and distribution of the article with the strict proviso that no changes or edits are made and the original work is properly cited (including links to both the formal publication through the relevant DOI and the license). See: https://creativecommons.org/licenses/by-nc-nd/4.0/.

(Editor: Jessica Liao, TBCR, tbcr@amegroups.com)

doi: $10.21037 /$ tbcr.2020.03.01

Cite this article as: Liao J. Dr. Zefei Jiang: our journey beyond the stars and seas. Transl Breast Cancer Res 2020;1:9. 